\title{
Маркетинг
}

УДК 339

КОМБАРОВА ИРИНА ВЛАДИМИРОВНА

к.т.н., доиент, ФБГБОУ ВО «Воронежский государственный технический университет», e-mail: irina.v.borisova@mail.ru

БОРИСОВА АЛЕКСАНДРА АНДРЕЕВНА

бакалавр ФБГБУ ВО «Воронежский государственный технический университет», e-mail: irina.v.borisova@mail.ru

\section{ПРИМЕНЕНИЕ ТЕХНОЛОГИЙ ЦИФРОВОГО МАРКЕТИНГА НА ПАРФЮМЕРНО-КОСМЕТИЧЕСКОМ РЫНКЕ}

\begin{abstract}
Аннотауия. Џель работы. Џелью работы является анализ основных тендениий влияния формирующихся ииировых технологий на рынок парфюмерии и косметики, как в количественном, так и в качественном измерении. Метод или методология проведения работы. Применялся широкий спектр методов сбора фактического материала и его обработ$к и$, проведены собственные исследования особенностей потребительского поведения на основе первичных источников информации. Проанализированы данные мониторинга и

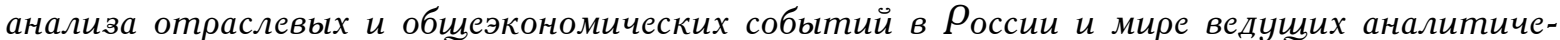
ских агентств. Результаты. Исследование включает описание тенденций развития российского и зарубежного парфюмерно-косметического ритейла, что позволяет сравнить развитие российского рынка с рынками других стран, выявить аналогии и построить прогноз развития. На основе анализа вторичных данных выявлены ключевые направления дальнейшего развития парфюмерно-косметического ритейла. Сделан вывод о том, что развитие интернет-технологий вынуждает бизнес перестраивать маркетинговую стратегию под изменившуюся внешнюю среду и активно использовать digital-инструменты, принципиально менять свою систему маркетинговых коммуникаций, формировать виртуальную инфраструктуру бизнеса, развивать интернет-маркетинг, управление взаимоотношениями с клиентами на основе CRM-систем, внедрять маркетинг-аналитику (или бизнес-аналитику) и т. п. Развитие иифровых технологий приводит к тому, что важным фактором конкурентоспособности становится скорость ведения бизнеса, внешней и внутренней логистики, бизнес-процессов, принятия и реализации управленческих

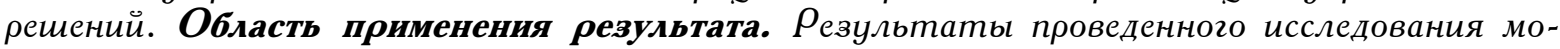
гут быть использованы в качестве рекомендаиий российскими компаниями по использо-

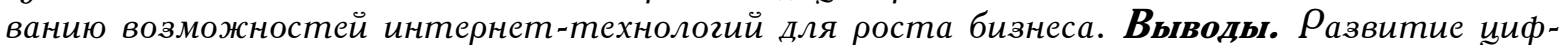
ровых технологий и меняющиеся потребительские тренды приводят к необходимости использования digital-инструментов маркетинга для успешного развития бизнеса.
\end{abstract}

Ключевые слова: ритейл, косметика и парфюмерия, Интернет, иифровой маркетинг.

KOMBAROVA IRINA VLADIMIROVNA

Candidate of Technical Sciences, Associate Professor, FSBEI of HE

"Voronezh State Technical University", e-mail: irina.v.borisova@mail.ru

BORISOVA ALEXANDRA ANDREEVNA

Bachelor of FSBEI of HE "Voronezh State Technical University", e-mail: irina.v.borisova@mail.ru

\section{USING TECHNOLOGIES OF DIGITAL MARKETING IN THE PERFUME AND COSMETIC MARKET}


Abstract. The goal of the study. The goal of the study is analyzing the main tendencies of impact of forming digital technologies in the perfume and cosmetics market, both quantitatively and qualitatively. The method or methodology of completing the study. We have used a wide variety of methods of collecting the factual material and its processing; we have performed our own studies of the features of consumer behaviour based on the primary sources of information. We have analyzed the data of monitoring and analysis of industry specific and general economic events in Russia and in the world of leading analytical agencies. The results. The study includes a description of tendencies of development of Russian and foreign perfume-cosmetic retail which allows to compare the development of the Russian market with markets of other countries, find analogies and build the forecast of development. Based on an analysis of the secondary data we have found the key areas of focus for further development of perfume and cosmetic retail. We have come to a conclusion that the development of Internet technologies makes business rebuild the marketing strategy following the changed external environment, as well as actively use digital instruments, fundamentally change its system of marketing communications, form a virtual infrastructure of business, develop Internet marketing, management of interactions with clients based on CRM-systems, implement marketing analytics (or business analytics), etc. The development of digital technologies leads to the fact that the speed of business of external and internal logistics, business processes, making and implementing managerial decisions become important factors of a competitive ability. The area of application of the result. The results of the study completed may be used as recommendations by Russian companies to use the capabilities of Internet technologies for business growth. The conclusions. The development of digital technologies and the changing consumer trends lead towards the need to use digital instruments of marketing for a successful development of business.

Keywords: retail, cosmetics and perfume, the Internet, digital marketing.

Парфюмерно-косметический рынок - один из наиболее успешно и динамично развивающихся сегментов российского ритейла. В настоящее время российский рынок парфюмернокосметических товаров входит в топ-10 крупнейших рынков Европы. По данным Росстата, оборот розничной торговли парфюмерно-косметическими товарами в 2014 г. составил 437,8 млрд руб. с учетом НДС, что на 11,5\% выше показателя 2013 г. В 2015 г. темпы прироста составили $13,8 \%$ с учетом Крымского федерального округа и 12,6\% - без учета его показателей. В 2016 г. рост объема рынка замедлился и составил 5,4\%. В 2017 г. объем рынка увеличился на 7,1\% относительно 2016 г. Однако объем продаж в натуральном выражении сократился [1]. Это связано со снижением реальных доходов населения и ростом цен на продукцию. В сегменте дрогери у ритейлеров наиболее активно растут продажи в ходе проведения промоакций в связи с высокой ценовой чувствительностью потребителей в сегменте косметических товаров. Продолжается развитие специализированных интернет-магазинов по продаже косметики и парфюмерии. Онлайн-рынок парфюмерно-косметических товаров в 2016 г. вырос относительно 2015 г. на $23 \%$, а рост 2017 г. к 2016 г. составил 18\% [2]. Наблюдается рост концентрации лидеров в интернет-ритейле на фоне снижения выручки в стационарных магазинах и MLM [2], данные представлены в табл. 1.

Таблииа 1

Динамика розничной торговли по отдельным каналам продаж, \$ млрд

\begin{tabular}{|l|c|c|c|c|}
\hline \multicolumn{2}{|c|}{ Канал продаж } & \multicolumn{3}{c|}{ Годы } \\
\cline { 2 - 5 } & $\mathbf{2 0 1 5}$ & $\mathbf{2 0 1 6}$ & $\mathbf{2 0 1 7}$ & CAGR 2016/2017, \% \\
\hline Стационарная универсальная торговля & 11098 & 13399 & 14066 & 4,90 \\
\hline Выручка ТОП-20 крупнейших ритейлеров & 1638 & 1845 & 1824 & 2,20 \\
\hline Доля ТОП-20 (из 89 тыс.), \% & 14,80 & 13,80 & 13,00 & $\boldsymbol{\nabla}$ \\
\hline Дистанционные продажи: интернет-магазины & 330 & 719 & 837 & 20 \\
\hline Выручка ТОП-20 интернет-магазинов & 40 & 152 & 207 & 39 \\
\hline Доля ТОП-20 (из 40 тыс.), \% & 12 & 21 & 25 & $\mathbf{\Delta}$ \\
\hline Дистанционные продажи: МLМ & 129 & 171 & 184 & 7,4 \\
\hline Выручка ТОП-20 МLМ компаний & 41 & 53 & 53 & 5,3 \\
\hline Доля ТОП-20 (из 25 тыс.), \% & 32 & 31 & 29 & $\mathbf{\nabla}$ \\
\hline
\end{tabular}


Новый импульс развитию интернет-торговли парфюмерно-косметическими товарами придают специализированные офлайн-сети, открывающие собственные интернет-магазины. Косметика и парфюмерия входят в рейтинг ТОП-5 наиболее покупаемых в сети Интернет товаров, их за последний год приобретали, соответственно, 31,4\% интернет-покупателей в возрасте от 18 до 54 лет (5,2 млн россиян). Затраты на единовременную покупку косметики и парфюмерии через интернет-магазины составляют 2767 руб. (с НДС), наиболее высокий средний чек в Московской области и Москве (3756 руб. и 3134 руб., соответственно), в СанктПетербурге - 3094 руб., что сопоставимо с Москвой, а вот в городах-миллионниках средний чек был существенно меньше - 2653 руб. Частота покупки - в среднем 6,6 раз в год, причем основными покупателями, безусловно, являются женщины - 77,3\% от общего числа покупателей. Количество людей, ежемесячно пользующихся Интернетом, постоянно увеличивается, согласно данным TNS Web Index, интернет-аудитория в России (12+) составляет 85,9 млн пользователей [3], и этот показатель продолжает расти. Кроме того, повышаются рекламные затраты на Интернет: по результатам первого квартала 2016 г. затраты на размещение в Интернете на рекламном рынке составляют 23,7 млрд руб., что означает второе место после ТВ. Более того, Интернет является медиаканалом с наибольшим приростом: $+31 \%$ по сравнению с соответствующим периодом 2015 г. [4].

Результаты. Интернет развивается не только в количественном, но и в качественном измерении. Растет мобильная интернетизация и геймификация жизни и бизнеса:

- усиливается влияние непрофессионального мнения на потребительский выбор - по рекомендациям, рейтингам, блогам, «красотным» приложениям (снижение лояльности к бренду, переключаемость на новые продукты и концепции) [5];

- глобализация и непрерывность процесса покупок - простота покупки в любой точке мира из любой точки мира (рост трансграничных интернет-покупок из КНР, ЕС, США);

- мгновенность и полнота информированности благодаря мобильному Интернету и смартфонам (mobile-first world);

- клиент почти непрерывно находится онлайн, мобильное устройство - самая эффективная точка контакта, так как дает клиенту возможность выбрать диалог в удобном ему режиме [6].

На рынке парфюмерии и косметики практика показывает динамичный рост кликов с тематических площадок по отношению к поисковым ресурсам. Это говорит о том, что потребители воспринимают советы на профильных ресурсах как рекомендации от экспертов, мнению которых можно доверять. Успешны контенты, созданные блогерами и бьюти-инфлюэнсерами, которые упоминают определенные продукты. Самый удачный пример UGC - user generated content ролики 'How to' с инструкциями по созданию макияжа [7]. Для рекламодателя это открывает широкие возможности по фокусному воздействию на покупателей с помощью специальных проектов, тематических обзоров, обучающего пользованию контента, дисплейной рекламы. К тому же, правильный подбор тематических ресурсов для размещения рекламных сообщений помогает выстроить в сознании потребителей нужный образ бренда за счет психологического переноса имиджа площадки на имидж рекламируемой марки. Кроме того, за каждым продуктом должна быть интересная история. Имидж известных брендов перестает работать [8]. Необходимы свежие, новые, нетривиальные концепты. Еще один рычаг для увеличения онлайн-продаж - это технологии дополненной реальности. Крупные компании запускают приложения, размещают в магазинах специальные экраны, для того чтобы покупатели могли «примерить» макияж или попробовать новинку мгновенно и совершить покупку. Самые известные приложения: L'Oreal Make-Up Genius, Brow Genie (Benefit), Lancome Virtual Mirrow. Интернет увеличивает число импульсных покупок. Доля спонтанных покупок в Beauty ecommerce составляет $30 \%$ от всех заказов, а более $45 \%$ потребителей принимают решение в течение 24 часов [9]. Выигрышной стратегией в данном случае является применение тех инструментов, которые минимизируют число действий по покупке: интеграция в Yandex и Google Markets, включая Market Place, размещение в геолокационных сервисах и каталогах, ремаркетинг, триггерный direct marketing, real-time персонализация сайта и др. [10].

Скорость ведения бизнеса внешней и внутренней логистики, бизнес-процессов, принятия и реализации управленческих решений становится более важным фактором конкурентоспособности, чем стоимость производства [11]: 
- автоматизация на основе алгоритмики (удаленный мониторинг с контекстным распознаванием в реальном времени);

- QRM;

- бизнес-аналитика больших чисел;

- сокращение срока жизни эксклюзива.

Формируется виртуальная инфраструктура бизнеса:

- сервисная робототехника: серийный выпуск устройств, подключенных к Интернету; снижение себестоимости создания единицы подключенных устройств;

- интеллектуальные системы управления: обработка больших данных персонализация во всем [12];

- производственные технологии: аддитивное производство, виртуальная и дополненная реальность, облачное хранение и обработка данных, 3D-принтинг: одежда, строительство, стоматология, фармацевтика и др. [13].

Развиваются небанковские структуры - авторы трансформационных изменений отрасли, снижающих стоимость финансовых операций для частных и корпоративных клиентов: веб- и мобайл-платежи доступны из любой точки - непрерывность и бесконтактность покупок (Samsung Pay, Apple Рау в России (Сбербанк, ВТБ, Альфа-банк и Тинькофф Банк, Бинбанк, Яндекс.Деньги, Райффайзенбанк, Открытие и др.) [14].

Развитие Внтернет-технологий вынуждает бизнес перестраивать маркетинговую стратегию под изменившуюся внешнюю среду и активно использовать digital-инструменты [15].

Цифровой маркетинг подразумевает персонализированный подход, а это значит, что вы должны иметь представление о потребностях, предпочтениях, интересах и других данных вашего потенциального клиента. Еще одной специфической чертой цифрового маркетинга является его информационная направленность [16].

Цифровой маркетинг разделяют на используемый в онлайн-пространстве и используемый в офлайн-пространстве. Каждому из видов соответствуют свои инструменты реализации [17], представленные в табл. 2.

Таблииа 2

\section{Инструменты реализации цифрового маркетинга}

\begin{tabular}{|c|c|c|}
\hline \multicolumn{2}{|r|}{ Онлайн-пространство } & Офлайн-пространство \\
\hline SEO оптимизация & $\begin{array}{c}\text { Оптимизируйте ваш сайт под запросы пользователей, } \\
\text { это позволит получить больше посетителей }\end{array}$ & QR-коды на различных источниках \\
\hline Контекстная реклама & $\begin{array}{c}\text { Непосредственно связана с оптимизацией. } \\
\text { Представляет собой рекламные объявления (ссылки), } \\
\text { которые появляются на ресурсах с тематикой, } \\
\text { соответствующей объявлению }\end{array}$ & \\
\hline Баннерная реклама & $\begin{array}{c}\text { Представляет собой рекламное изображение, которое } \\
\text { располагается на какой-либо части страницы } \\
\text { выбранного вами Интернет-ресурса }\end{array}$ & Телевизионная реклама \\
\hline Таргетинг & $\begin{array}{c}\text { Персонализированное рекламное объявление в соци- } \\
\text { альной сети, ведущее на ваш сайт (страницу) }\end{array}$ & Радиореклама \\
\hline Вирусная реклама & $\begin{array}{c}\text { Реклама, которую распространяют в Интернете сами } \\
\text { пользователи }\end{array}$ & \multirow{3}{*}{ СМС-сообщения } \\
\hline Email-рассылка & $\begin{array}{c}\text { Персонализированные электронные письма } \\
\text { рекламного содержания }\end{array}$ & \\
\hline Push и Рор uр окна & Всплывающие на выбранном ресурсе рекламные окна & \\
\hline Нативная реклама & $\begin{array}{c}\text { Естественная реклама на выбранных ресурсах, напри- } \\
\text { мер, статья на какую-либо тематику с упоминанием } \\
\text { вашего продукта }\end{array}$ & \\
\hline $\begin{array}{c}\text { Реклама в мобильных } \\
\text { приложениях }\end{array}$ & $\begin{array}{c}\text { Разнообразная реклама, встроенная в мобильные } \\
\text { приложения }\end{array}$ & \\
\hline
\end{tabular}


Для эффективного использования каждого из этих инструментов, необходимо разработать план digital-стратегии, провести оценку эффективности Интернет-кампании и управлять репутационными рисками. Процесс построения рекламной кампании в Интернете включает следующие основные этапы [18]:

1. Определение цели цифровой рекламной кампании. Они должны быть оцифрованы, то есть представлены в виде конкретных числовых значений.

2. Определение целевой аудитории рекламной кампании. Она должна совпадать с целевой аудиторией продукта, который вы продвигаете.

3. Определение конкурентного преимущества продукта, которое необходимо выразить в коммуникационном сообщении.

4. Выбор каналов распространения коммуникационного сообщения. Разработка коммуникационного сообщения, а также его оформления, соответствующего выбранным каналам.

5. Планирование бюджета и определение сроков.

6. Определение показателей для оценки эффективности по каждому каналу.

7. Контроль, анализ результатов.

Основные цели: получение сообщества лояльных, вовлеченных в жизнь бренда потребителей, готовых распространять положительную информацию о бренде (CRM-база лояльных пользователей, готовых к постоянным активностям); поддержка рекламных акций (ATL, BTL и пр.). Поддержка офлайн-коммуникаций (усиление других каналов рекламы), конвертация подписчиков. Для достижения максимального эффекта необходимо сочетать эффективные рабочие механики с инновационными методами. Основные механики продвижения в соцмедиа [19]:

- размещение в сообществах интересной информации;

- приглашение в сообщества;

- вовлечение сотрудников и партнеров, освещение событий;

- активный репост;

- фолловеры;

- таргетированная реклама;

- игры;

- офлайн-присутствие;

- конвертация сайта и е-mail рассылки.

Привлекая пользователей в сообщество, нельзя забывать о развитии их активности: взаимодействовать с ними, вызывать интерес к компании. Двумя главными составляющими вовлечения пользователей в жизнь сообщества являются контент и коммуникации. Эти элементы напрямую взаимосвязаны между собой. Контент должен соответствовать следующим требованиям: 1. Актуальность. 2. Влияние на эмоции аудитории. 3. Брендированность. 4. Качественное оформление. Безусловно, текст является важной составляющей контента в сообществе, но значимую роль здесь также играет и его визуализация [20].

Digital-маркетинг постоянно прогрессирует, появляется все больше новых инструментов для взаимодействия с целевой аудиторией, что собственно и является самой главной целью. Потребители самостоятельно создают необходимый им продукт или услугу, могут сами непосредственно контактировать с производителями, комментировать и отмечать положительные стороны. Также это шанс для компаний с небольшими капиталовложениями, которые могут продвинуть свой продукт, донести информацию о своих товарах и услугах до потенциальных покупателей.

Литература

1. ФCГC. -URL: http://www.gks.ru/free_doc/new_site/business/torg/rozn/rozn26.xls/.

2. РБК-исследования рынков. Российский парфюмерно-косметический рынок - один из самых крупнейших в Европе : данные о рынке. - URL : www.marketing.rbk.ru

3. TNS Web Index Poccus 12+, мapm 2016. - URL : http://www.tns-global.ru/services/media/.

4. АКАР : Объемы рекламы в средствах ее распространения в январе - марте 2016 года. - URL : http:// www.akarussia.ru/knowledge/market_size/id6703 (Дата обращения: 13.05.2016).

4. Блэкуэлл, Р., Миниард, П., Энджел, Дж. Поведение потребителей. - 10-е изд. ; пер. с англ. - СПб. :

Питер,

5.Барнетт, Дж., Мориарти, С. Маркетинговые коммуникачии : интегрированный подход. - М. : Питер, 2011 .

6. Chaffey, D., Ellis-Chadwick, F. Digital marketing. - Upper Saddle River : Pearson, 2016. 
7. Ryan, D. Understanding digital marketing : marketing strategies for engaging the digital generation. London Kogan Page, $\quad 2016$. 8. Dodson, I. The digital marketing playbook. - New Jersey : John Wiley \& Sons, Inc., 2016.

9. Anjos, M., Cheng, R., Currie, C. Optimal pricing policies for perishable products // European Journal of Operational Research. 2005. Vol. 166. No. 1. P. 246-254.

10. Bernstein, F., Federgruen, A. Pricing and replenishment strategies in a distribution system with competing retailers // European Journal of Operational Research. 2003. Vol. 51. No. 3. P. 409-426.

11. Bichler, M., Lawrence, R. D., Kalagnanam, J., Lee, H. S., Katircioglu, K., Lin, G. Y., King, A. J., Lu, Y. Applications of flexible pricing in business-to-business electronic commerce // IBM Systems Journal. 2002. Vol. 41. No. 2. P. 287-302.

12. Biller, S., Chan, L. M. A., Simchi-Levi, D., Swann, J. Dynamic pricing and the direct-to-customer model in the automotive industry // Electron Commerce Journal. 2005.

13. Голова, А. Г. Интегрированные маркетинговые коммуникации // Маркетинг в России и за рубежом. 2009. № 10. C. 37-46.

14. Данченок, Л. А. Маркетинг в соииальных медиа. Интернет-маркетинговые коммуникаиии : учеб. пособие ; под ред. Л.А. Данченок. - ППб. : Питер, 2013.

15. АКАР: Объемы рекламы в средствах ее распространения в январе - марте 2016 года. - URL : http:// www.akarussia.ru/knowledge/market_size/id6703 (Дата обращения: 13.05.2016).

16. Кононов, В. О., Черненко, В. А. Инновачионные методы маркетинга в современной экономике. - СПб. : Инфо-Да, 2008.

17. Ли, Ч. Взрывная Wеb-волна : как добиться успеха в мире, преображённом интернет-технологиями / Ч. Ли, Дю. Бернофф ; пер. с англ. - М. : Альпина Паблишерз, 2010.

18. Луков, В. А. Соииальное проектирование / В. А. Луков. - М. : Флинта, 2009.

19. Одден, Л. Продающий контент : как связать контент-маркетинг, SЕО и соииальные сети в единую систему / Ли Одден; пер. с англ. В. Иващенко. - М. : Манн, Иванов и Фербер, 2014.

20. Романов, А. А., Панько, А. В. Маркетинговые коммуникации. - 2-е изд., перераб. и доп. - М. :ЭКСМО, 2011.

21. Халилов, Д. Маркетинг в сочиальных сетях / Д. Халилов. - М. : Манн, Иванов и Фербер, 2013.

22. Халилов, Д. SММ. - М. : Манн, Иванов и Ферберов, 2014.

\section{References:}

1. FSGS. - URL : http://www.gks.ru/free_doc/new_site/business/torg/rozn/rozn26.xls/.

2.. RBC market research. The Russian perfume and cosmetics market is one of the largest in Europe : Market data. - URL : www.marketing.rbk.ru.

3. TNS Web Index Россия 12+, мapm 2016. - URL : http://www.tns-global.ru/services/media/.

4. AKAR : Volumes of advertising in means of its distribution in January - March 2016. - URL : http:// www.akarussia.ru/knowledge/market size/id6703 (Date of the application:13.05.2016).

4. Blackwell, R., Miniard, P., Angel, J. Consumer behavior. - 10th ed. ; Transl. with English. - St. Petersburg : Peter, 2007.

5. Barnett, J., Moriarty, S. Marketing Communications : The integrated approach. - M. : Peter, 2011.

6. Chaffey, D., Ellis-Chadwick, F. Digital marketing. - Upper Saddle River : Pearson, 2016.

7. Ryan, D. Understanding digital marketing : marketing strategies for engaging the digital generation. - London : Kogan Page, 2016.

8. Dodson, I. The digital marketing playbook. - New Jersey : John Wiley \& Sons, Inc., 2016.

9. Anjos, M., Cheng, R., Currie. C. Optimal pricing policies for perishable products // European Journal of Operational Research. 2005. Vol. 166. No. 1. P. 246-254.

10. Bernstein, F., Federgruen, A. Pricing and replenishment strategies in a distribution system with competing retailers // European Journal of Operational Research. 2003. Vol. 51. No. 3. P. 409-426.

11. Bichler, M., Lawrence, R. D., Kalagnanam, J., Lee, H. S., Katircioglu, K., Lin, G. Y., King, A. J., Lu, Y. Applications offlexible pricing in business-to-business electronic commerce // IBM Systems Journal. 2002. Vol. 41. No. 2. P. 287-302.

12. Biller, S., Chan, L. M. A., Simchi-Levi, D., Swann, J. Dynamic pricing and the direct-to-customer model in the automotive industry // Electron Commerce Journal. 2005.

13. Golova, A. G. Integrated marketing communications // Marketing in Russia and abroad. 2009. No. 10. P. 37 -46 .

14. Danchenok, LA Marketing in social media. Internet Marketing Communications : Textbook. ; ed. L.A. Dunchenok. - St. Petersburg: Peter, 2013.

15. AKAR: Volumes of advertising in the means of its distribution in January-March 2016. URL: http:// www.akarussia.ru/knowledge/market_size/id6703 (Дата обращения: 13.05.2016)

16. Kononov, $V$. O., Chernenko, $\bar{V}$. A. Innovative methods of marketing in the modern economy. - St. Petersburg : Info-Yes, 2008.

17. Lee, C. Blasting Web_Wall : How to succeed in a world transformed by Internet technologies / C. Lee, J. Bernoff ; trans. with English. - M. : Alpina Publishers, 2010.

18. Lukov, V. A. Social Design /VA Lukov. - M. : Flint, 2009.

19. Odden, L. Selling content : How to link content marketing, SEO and social networks into a single system / Lee Odden ; trans. with English. V. Ivashchenko. - M. : Mann, Ivanov and Ferber, 2014.

20. Romanov, A. A., Panko, A.V. Marketing communications. - 2nd ed., revised and additional. - M. : EKSMO, 2011.

21. Khalilov, D. Marketing in social networks / D. Khalilov. - M. : Mann, Ivanov and Ferber, 2013.

22. Khalilov, D. SMM. - M. : Mann, Ivanov and Ferber, 2014. 